
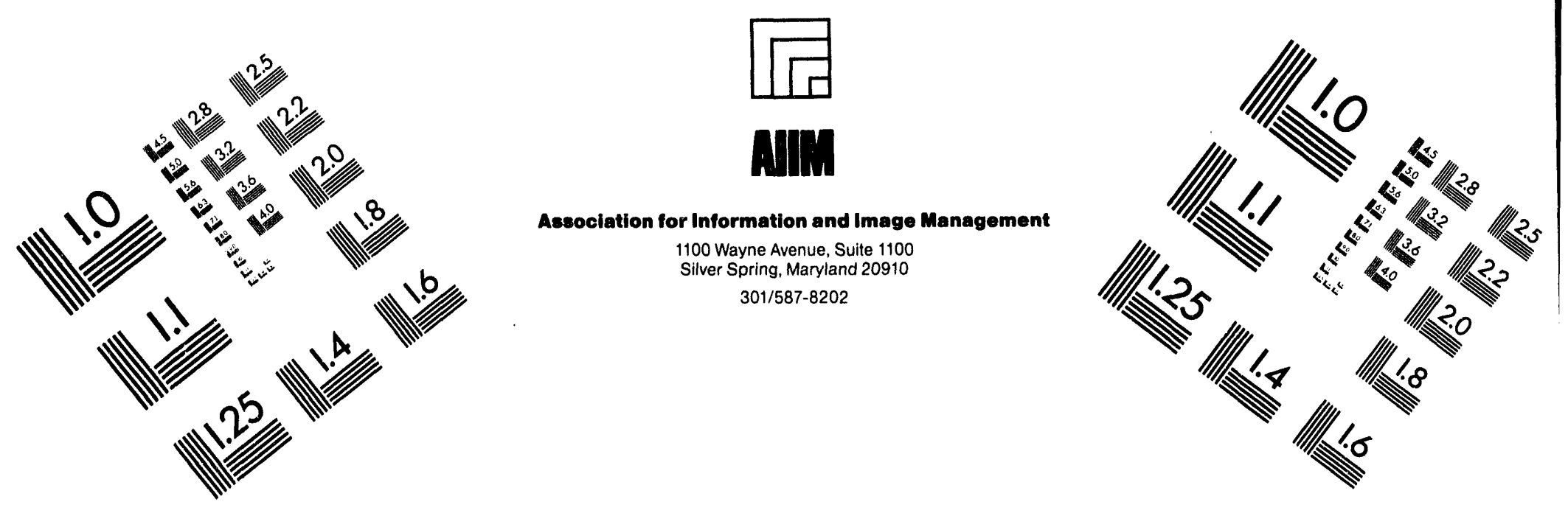

Centimeter

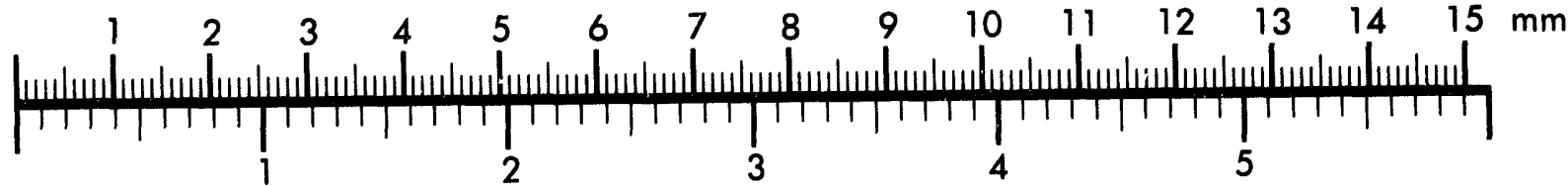
Inches
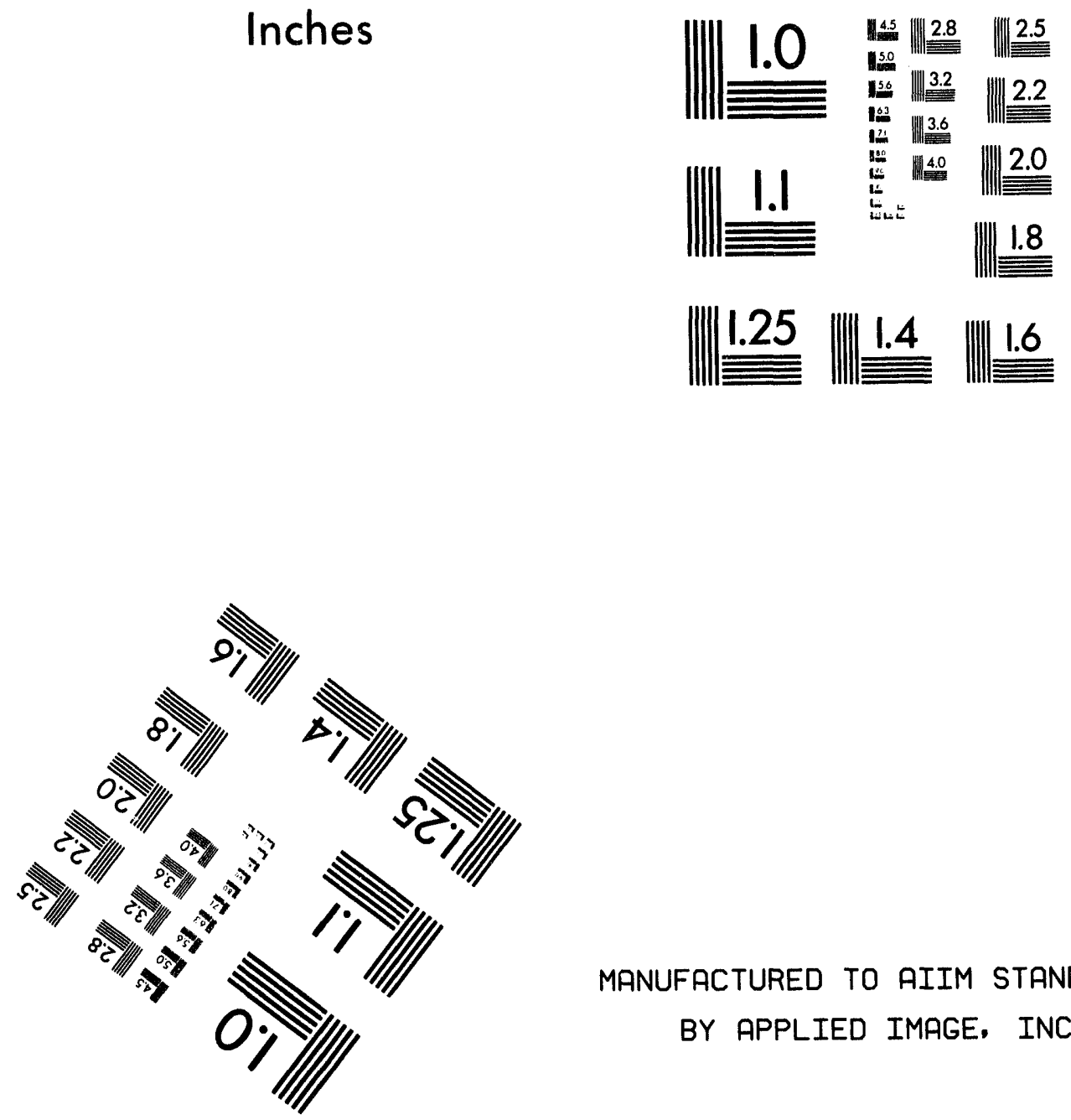

MANUFACTURED TO AIIM STANDARDS

BY APPLIED IMAGE, INC.

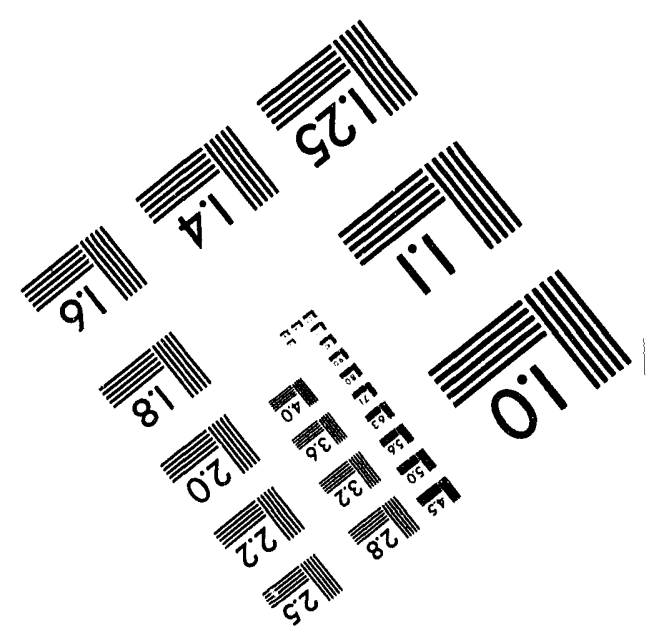



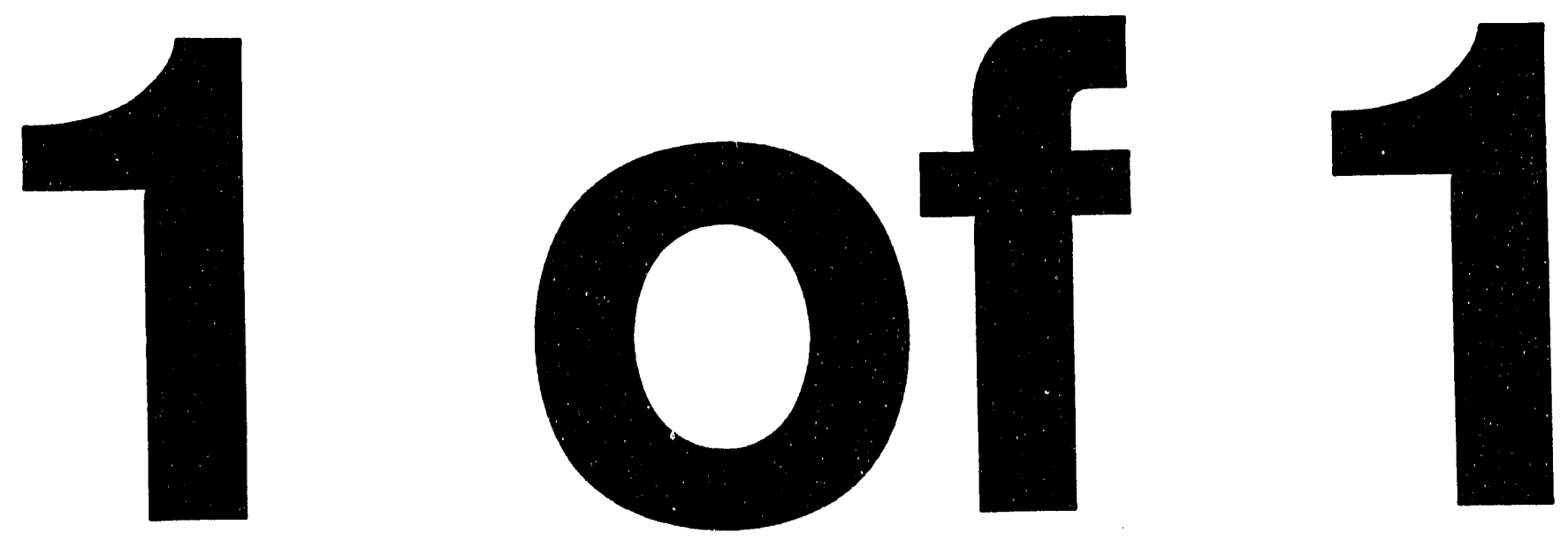
NUREG/CR-6190

Vol. 2

\section{Protection Against Malevolent \\ Use of Vehicles at \\ Nuclear Power Plants}

Vehicle Barrier System Selection Guidance

Manuscript Completed: July 1994

Date Published: August 1994

Prepared by

D. T. Nebuda

U.S. Army Corps of Engineers, Omaha District

Protective Design-Mandatory Center of Expertise

215 North 17th Street

Omaha, NE 68102-4978

Prepared for

Division of Radiation Safety and Safeguards

Office of Nuclear Reactor Regulation

U.S. Nuclear Regulatory Commission

Washington, DC 20555-0001

NRC FIN A0400 


\begin{abstract}
This manual provides a simplified procedure for selecting land vehicle barriers that will stop the design basis vehicle threat adopted by the U.S. Nuclear Regulatory Commission. Proper selection and construction of vehicle barriers should prevent intrusion of the design basis vehicle. In addition, vital safety related equipment should survive a design basis vehicle bomb attack when vehicle barriers are properly selected, sited, and constructed. This manual addresses passive vehicle barriers, active vehicle barriers, and site design features that can be used to reduce vehicle impact velocity.
\end{abstract}




\section{Contents}

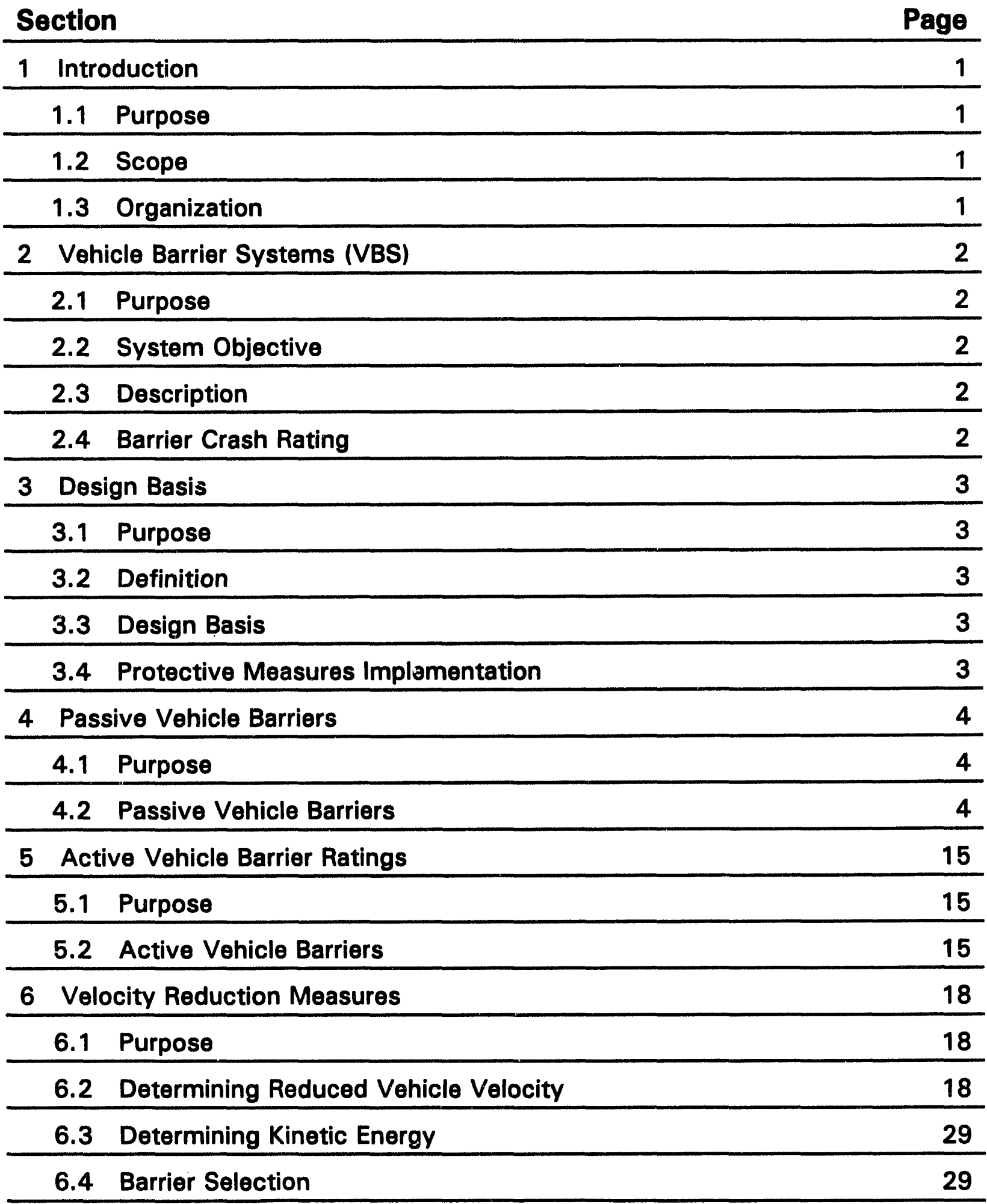




\section{Contents (Cont'd)}

Section

Page

7 Other Vehicle Barriers

8 Documentation 31

9 Conclusions

32

Figures

\begin{tabular}{|c|c|c|}
\hline 4.1 & Minimum Construction Requirements for Concrete Planters & 8 \\
\hline 4.2 & Minimum Construction Requirements for Jersey Barriers & 9 \\
\hline 4.3 & Minimum Construction Requirements for Bollards & 10 \\
\hline 4.4 & Chain-Link Fence With Cables & 11 \\
\hline 4.5 & Deadman Detail & 12 \\
\hline 4.6 & Intersect of Two Cable Runs Detail & 13 \\
\hline 4.7 & Corner or End Post Detail & 14 \\
\hline 6.1 & Vehicle Velocity on Curves & 19 \\
\hline 6.2 & Vehicle Velocity from Dead Start & 20 \\
\hline 6.3 & Perimeter Barriers Used as Traffic Obstacles & 21 \\
\hline 6.4 & Application of Traffic Obstacles & 22 \\
\hline 6.5 & Obstacle Spacing vs. Vehicle Velocity & 23 \\
\hline 6.6 & Example - Vehicle Velocity on Curves & 25 \\
\hline 6.7 & Example - Vehicle Velocity from Dead Start & 26 \\
\hline 6.8 & Example - Vehicle Velocity With Initial Velocity & 27 \\
\hline 6.9 & Example - Obstacle Spacing vs. Vehicle Velocity & 28 \\
\hline \multicolumn{3}{|c|}{ Tables } \\
\hline 4.1 & Concrete Planter Ratings & 5 \\
\hline 4.2 & Jersey Barrier Ratings & 5 \\
\hline 4.3 & Bollard Ratings & 6 \\
\hline 4.4 & Cabled Fence Ratings & 7 \\
\hline 5.1 & Results of Active Vehicle Barrier Tests & 15 \\
\hline
\end{tabular}

NUREG/CR-6190, VOL. 2 


\section{SECTION 1 - INTRODUCTION}

\subsection{Purpose}

This manual provides a simplified procedure that may be used to select vehicle barriers to prevent intrusion by the design basis vehicle threat adopted by the U.S. Nuclear Regulatory Commission. The procedure presented can be used to determine the adequacy of existing vehicle barriers or it can be used for the planning of new vehicle barriers. The user of this manual should either have a background in civil engineering or should consult a civil engineer when using the manual.

\subsection{Scope}

This manual presents guidance for vehicle barriers with known crash ratings. The procedure presented is an accepted way of demonstrating conformance; however, it is not exclusive. Other procedures based on sound scientific and engineering principles are also acceptable. Barriers not discussed are not disallowed and means of demonstrating conformance for these barriers are discussed.

\subsection{Organization}

The procedure for controlling vehicle intrusion is organized into the sections listed below.

Section Topic

2 Vehicle Barrier Systems

3 Design Basis

4 Passive Vehicle Barriers

5 Active Vehicle Barrier Ratings

6 Velocity Reduction Measures

7 Other Vehicle Barriers

8 Documentation

9 Conclusions 


\section{SECTION 2 - VEHICLE BARRIER SYSTEMS (VBS)}

\subsection{Purpose}

This section gives the user a basic knowledge of the components of a VBS and the methods by which these components are rated for intrusion resistance.

\subsection{System Objective}

The purpose of a VBS is to prevent intrusion of vehicles into an area. The VBS must be capable of resisting vehicle impact and providing continuous protection in all areas where approach by land vehicle is possible. Additionally, VBS are sited to provide sufficient standoff distance from vital area barriers and vital safety related equipment to minimize damage that could be caused by a vehicle bomb. Additional standoff distance may be required for some vehicle barriers depending on their performance characteristics. This additional standoff distance required is cited in this manual where applicable. Refer to Volume 1 of this NUREG for further information on standoff distance.

\subsection{Description}

A VBS consists of two components--passive vehicle barriers and active vehicle barriers. Passive vehicle barriers are placed along the perimeter of the exclusive standoff zone where approach by land vehicle is possible except at points through which vehicle access is allowed. These barriers have no moving parts and are in a continuous "ready" position. Active vehicle barriers are used at points in the perimeter of an exclusive standoff zone through which vehicle access is allowed. These barriers are maintained in an active position and must be deactivated by authorized personnel to permit authorized vehicle access. At points that require infrequent vehicle access, removable passive barriers are sometimes used. Where active barriers are used, care must be taken to provide a consistent level of protection where the passive and active barriers interface. The VBS must not be vulnerable to unauthorized entry when an active vehicle barrier is allowing an authorized vehicle access. Both passive and active barriers are described in subsequent sections.

\subsection{Barrier Crash Rating}

For the purposes of this manual, vehicle barriers are rated based on the kinetic energy resisted. The kinetic energy resistance measures the capacity of a barrier to stop a vehicle of a particular gross weight at a given velocity. This capacity is measured in kinetic energy according to equation $2-1$.

$$
\begin{aligned}
& K E=0.03344 \times W \times V^{2} \\
& K E=\text { kinetic energy (foot-pounds) } \\
& W=\text { vehicle weight (pounds) } \\
& V=\text { vehicle velocity (miles per hour) }
\end{aligned}
$$

The barrier rating is typically determined through crash testing of full-scale barriers but may also be determined through detailed structural analysis. 


\section{SECTION 3 - DESIGN BASIS}

\subsection{Purpose}

This section defines the design basis threat and protection criteria that a vehicle barrier system (VBS) must resist.

\subsection{Definition}

The design threat that a VBS has to stop is a specified gross vehicle weight and impact velocity. These two parameters allow calculation of the kinetic energy that the VBS must resist.

\subsection{Design Basis}

The maximum parameters of the design basis vehicle threat and protection criteria can be found in Regulatory Guide 5.68. The kinetic energy associated with the gross vehicle weight and maximum velocity, $\mathrm{KE}_{\max }$, is the maximum kinetic energy that any VBS need resist. All this information has been determined by the Nuclear Regulatory Commission to be Safeguards Information, and it should be handled accordingly.

\subsection{Protective Measures Imple- mentation}

If site conditions do not provide for velocity reduction, the maximum velocity should be used in calculating the VBS requirements. If it can be demonstrated that site conditions prevent vehicles from attaining the maximum velocity at a point or points along the VBS perimeter, a lesser velocity can be used in calculating the VBS requirements for that point or points. Examples of site conditions that can reduce vehicle velocity include curved approach roads, inclines, ditches, and berms. Section 6 contains information on velocity reduction. The kinetic energy associated with the lesser velocity is calculated using equation 2-1. No vehicle barriers are needed in areas of the VBS perimeter that cannot be approached by land vehicle due to site topography. The velocity that is used to determine VBS requirements and the associated kinetic energy have been determined by the Nuclear Regulatory Commission to be Safeguards Information, and they should be handled accordingly. 


\section{SECTION 4 - PASSIVE VEHICLE BARRIERS}

\subsection{Purpose}

This section provides information from an existing database of passive vehicle barriers. Passive vehicle barrier ratings as well as construction details are contained in this section. If passive vehicle barriers other than those cited are used, or proposed for use, refer to section 7.

\subsection{Passive Vehicle Barriers}

Information on concrete planters, Jersey barriers, bollards, and cable reinforced fences is presented below. The information on these types of passive vehicle barrier systems includes typical construction details and kinetic energy ratings. If passive vehicle barriers are properly installed, have foundation designs consistent with local site conditions, and have kinetic energy ratings equal to or greater than $\mathrm{KE}_{\max }$, no additional site features to reduce velocity are required. The use of passive vehicle barriers with kinetic energy rating less than $\mathrm{KE}_{\max }$ requires the user to provide positive means for velocity reduction as discussed in section 6 .

\subsubsection{Basis of Ratings}

The barrier ratings presented are based on analytical modeling using the computer program BIRM (Barrier Impact Response Model) and other methods. Information on BIRM is contained in U.S. Army Corps of Engineers Protective Design - Mandatory Center of Expertise Technical Report PDC-TR 90-2, BIRM -- A Vehicle Barrier Response Model Using BARRIER VII.

\subsubsection{Foundations}

Barriers must be properly installed and must have foundation designs consistent with local site conditions. Ratings for different soil conditions are provided for Jersey barriers and bollards. Sandy loam, saturated clay, and stiff clay are described in geotechnical engineering and soil mechanics manuals. Base material is a double crushed, well-graded aggregate mixed with a binder material. This material is commonly used in highway and building foundation construction and is a suitable material for subgrade preparation. Soil type is not a major parameter for planters and cable reinforced fence.

\subsubsection{Concrete Planters}

Table 4.1 contains kinetic energy ratings for concrete planters in various foundation conditions. Figure 4.1 contains typical construction details for concrete planters. To be considered anchored, the planter must be embedded at least 1 foot, 6 inches into the foundation material, as illustrated in figure 4.1. Planters not meeting this embedment criteria should be considered unanchored.

\subsubsection{Jersey Barriers}

Table 4.2 contains kinetic energy ratings for Jersey barriers in various foundation conditions. Figure 4.2 contains typical construction details for Jersey barriers. To be considered anchored, the barriers must be secured to the foundation every 3 feet, 3 inches along the barrier with 1inch diameter by 3 -foot-long steel pins, alternating from side to side. Jersey barriers not meeting this criteria should be considered unanchored. 


\subsubsection{Bollards}

Table 4.3 contains kinetic energy ratings fol bollards in various foundation conditions. Figure 4.3 contains typical construction details for bollards.

\subsubsection{Cable Reinforced Fences}

Table 4.4 contains kinetic energy ratings for fence reinforced with various numbers and diameters of extra improved plow steel cables with various deadman spacings. Also contained in Table 4.4 are additional standoff requirements due to the performance characteristics of this type of vehicle barrier to provide adequate blast protection. Figures 4.4 through 4.7 contain typical construction details for cable reinforced fences.

Table 4.1 Concrete planter ratings

\begin{tabular}{lc} 
Foundation & $\begin{array}{c}\text { Kinetic Energy } \\
\text { Rating (ft-lb x 1000) }\end{array}$ \\
\hline Anchored & $\geq \mathrm{KE}_{\max }$ \\
Unanchored on Concrete & 94 \\
\hline
\end{tabular}

Table 4.2 Jersey barrier ratings

\section{Foundation}

\begin{tabular}{lc} 
Foundation & $\begin{array}{c}\text { Kinetic Energy } \\
\text { Rating }(\mathrm{ft}-1 \mathrm{~b} \mathrm{x} \mathrm{1000)}\end{array}$ \\
\hline Concrete & $\geq \mathrm{KE}_{\max }$ \\
Base Material & $\geq \mathrm{KE}_{\max }$ \\
Stiff Clay & $\geq \mathrm{KE}_{\max }$ \\
Saturated Clay & 205 \\
Sandy Loam & 268 \\
Unanchored on Concrete & 24 \\
\hline
\end{tabular}

Rating (ft-lb x 1000)

Kinetic Energy 
Table 4.3 Bollard ratings

\begin{tabular}{lc}
\multicolumn{1}{c}{ Foundation } & $\begin{array}{c}\text { Kinetic Energy } \\
\text { Rating }(\mathrm{ft}-\mathrm{lb} \times 1000)\end{array}$ \\
\hline 2 Feet on Center & \\
Base Material & $\geq \mathrm{KE}_{\max }$ \\
Stiff Clay & $\geq \mathrm{KE}_{\max }$ \\
Saturated Clay & $\geq \mathrm{KE}_{\max }$ \\
Sandy Loam & $\geq \mathrm{KE}_{\max }$ \\
3 Feet on Center & \\
& \\
Base Material & $\geq \mathrm{KE}_{\max }$ \\
Stiff Clay & $\geq \mathrm{KE}_{\max }$ \\
Saturated Clay & 268 \\
Sandy Loam & 205 \\
& \\
4 Feet on Center & \\
Base Material & $\mathrm{KE}_{\max }$ \\
Stiff Clay & 205 \\
Saturated Clay & 205 \\
Sandy Loam & 205 \\
\hline
\end{tabular}


Table 4.4 Cabled fence ratings

\begin{tabular}{|c|c|c|c|c|}
\hline $\begin{array}{l}\text { Deadmen } \\
\text { Spacing (ft) }\end{array}$ & $\begin{array}{l}\text { Cable } \\
\text { Diameter }\end{array}$ & $\begin{array}{c}\text { Number of } \\
\text { Cables }\end{array}$ & $\begin{array}{c}\text { Kinetic Energy } \\
\text { Rating (ft-lb x 1000) }\end{array}$ & $\begin{array}{l}\text { Additional Standoff } \\
\text { Required (ft) }\end{array}$ \\
\hline 200 & 1 inch & $\begin{array}{l}4 \\
3 \\
2 \\
1\end{array}$ & $\begin{aligned} \geq & \mathrm{KE}_{\max } \\
\geq & \mathrm{KE}_{\max } \\
& 340 \\
& 150\end{aligned}$ & $\begin{array}{l}30 \\
35 \\
40 \\
35\end{array}$ \\
\hline 200 & $3 / 4$ inch & $\begin{array}{l}4 \\
3 \\
2 \\
1\end{array}$ & $\begin{array}{c}\geq \mathrm{KE}_{\max } \\
340 \\
200 \\
100\end{array}$ & $\begin{array}{l}40 \\
40 \\
40 \\
40\end{array}$ \\
\hline 100 & 1 inch & $\begin{array}{l}4 \\
3 \\
2 \\
1\end{array}$ & $\begin{array}{r}340 \\
270 \\
150 \\
70\end{array}$ & $\begin{array}{l}20 \\
20 \\
20 \\
20\end{array}$ \\
\hline 100 & $3 / 4$ inch & $\begin{array}{l}4 \\
3 \\
2 \\
1\end{array}$ & $\begin{array}{r}200 \\
150 \\
100 \\
40\end{array}$ & $\begin{array}{l}20 \\
20 \\
20 \\
15\end{array}$ \\
\hline 50 & 1 inch & $\begin{array}{l}4 \\
3 \\
2 \\
1\end{array}$ & $\begin{array}{r}150 \\
100 \\
70 \\
40\end{array}$ & $\begin{array}{l}10 \\
10 \\
10 \\
10\end{array}$ \\
\hline 50 & $3 / 4$ inch & $\begin{array}{l}4 \\
3 \\
2 \\
1\end{array}$ & $\begin{array}{r}100 \\
70 \\
40 \\
20\end{array}$ & $\begin{array}{l}10 \\
10 \\
10 \\
10\end{array}$ \\
\hline
\end{tabular}




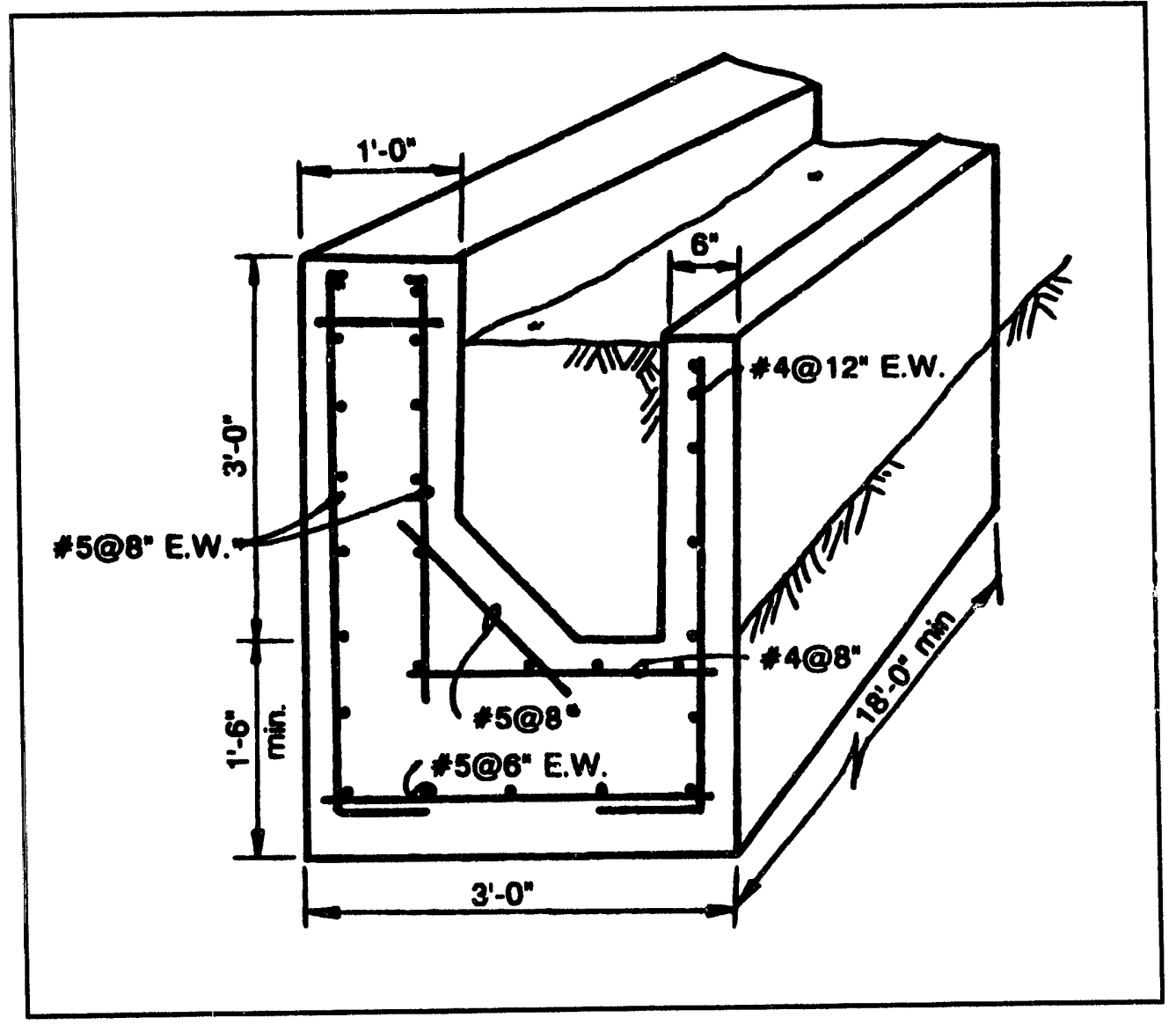

Figure 4.1 Minimum construction requirements for concrete planters 


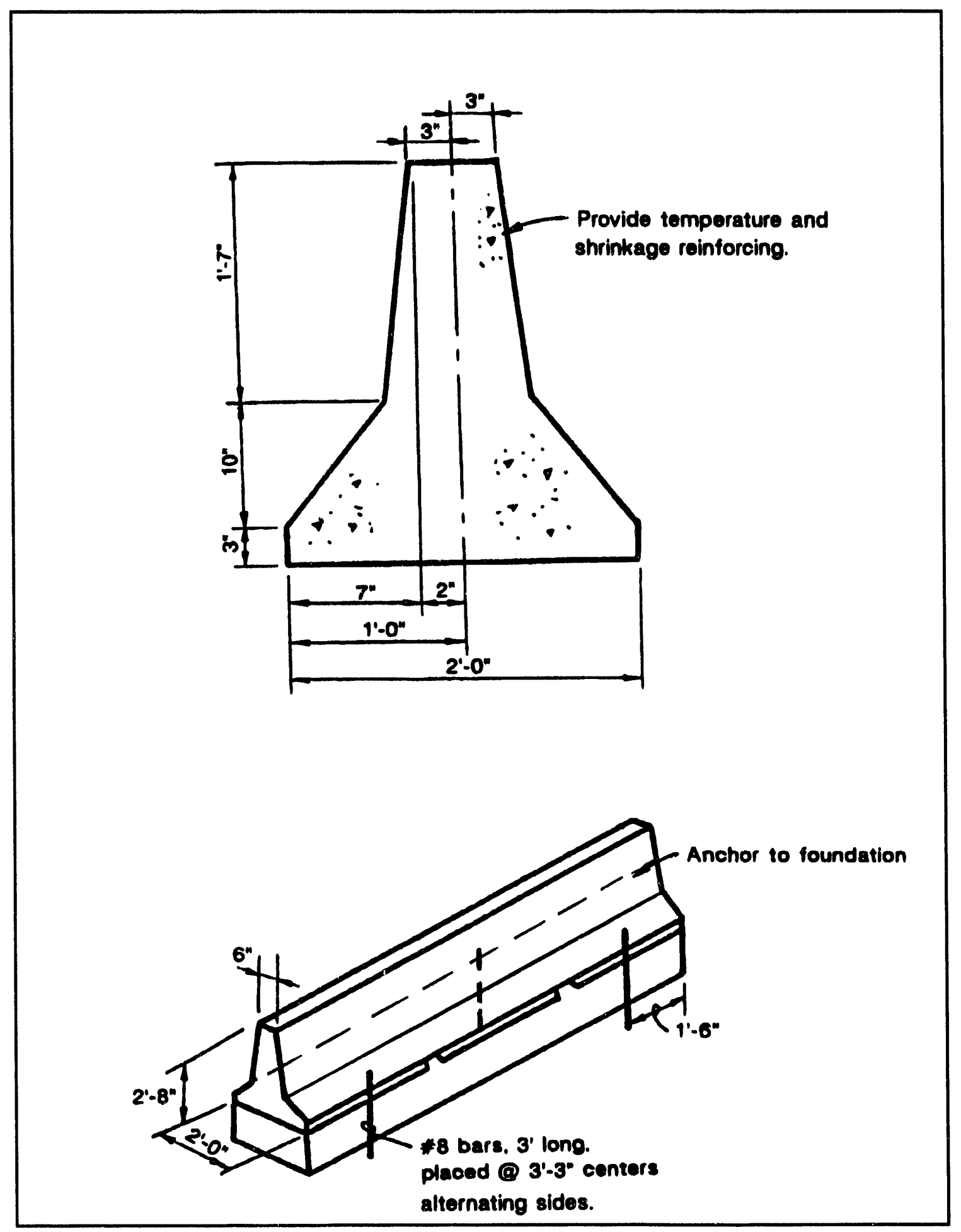

Figure 4.2 Minimum construction requirements for Jersey barriers 


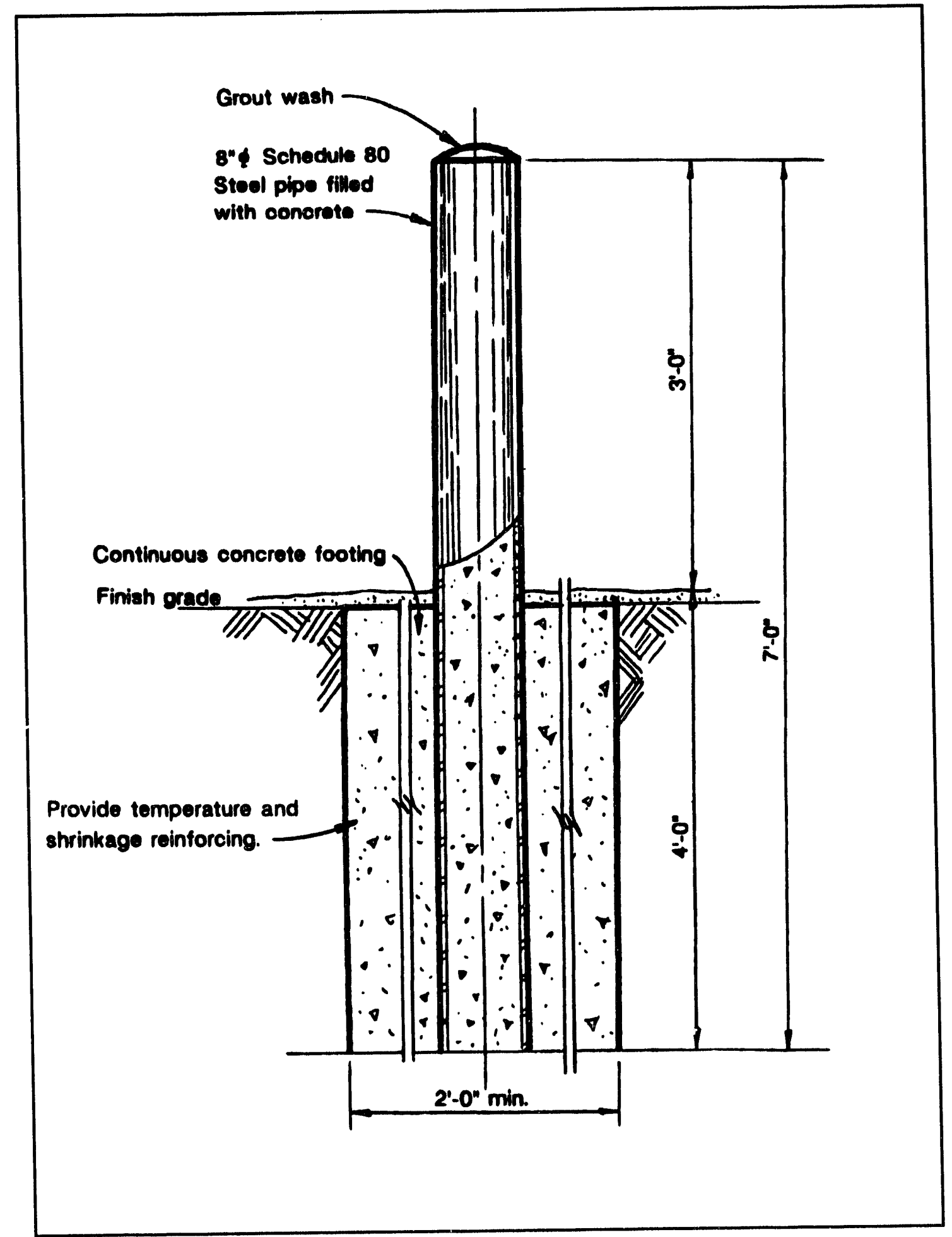

Figure 4.3 Minimum construction requirements for bollards 


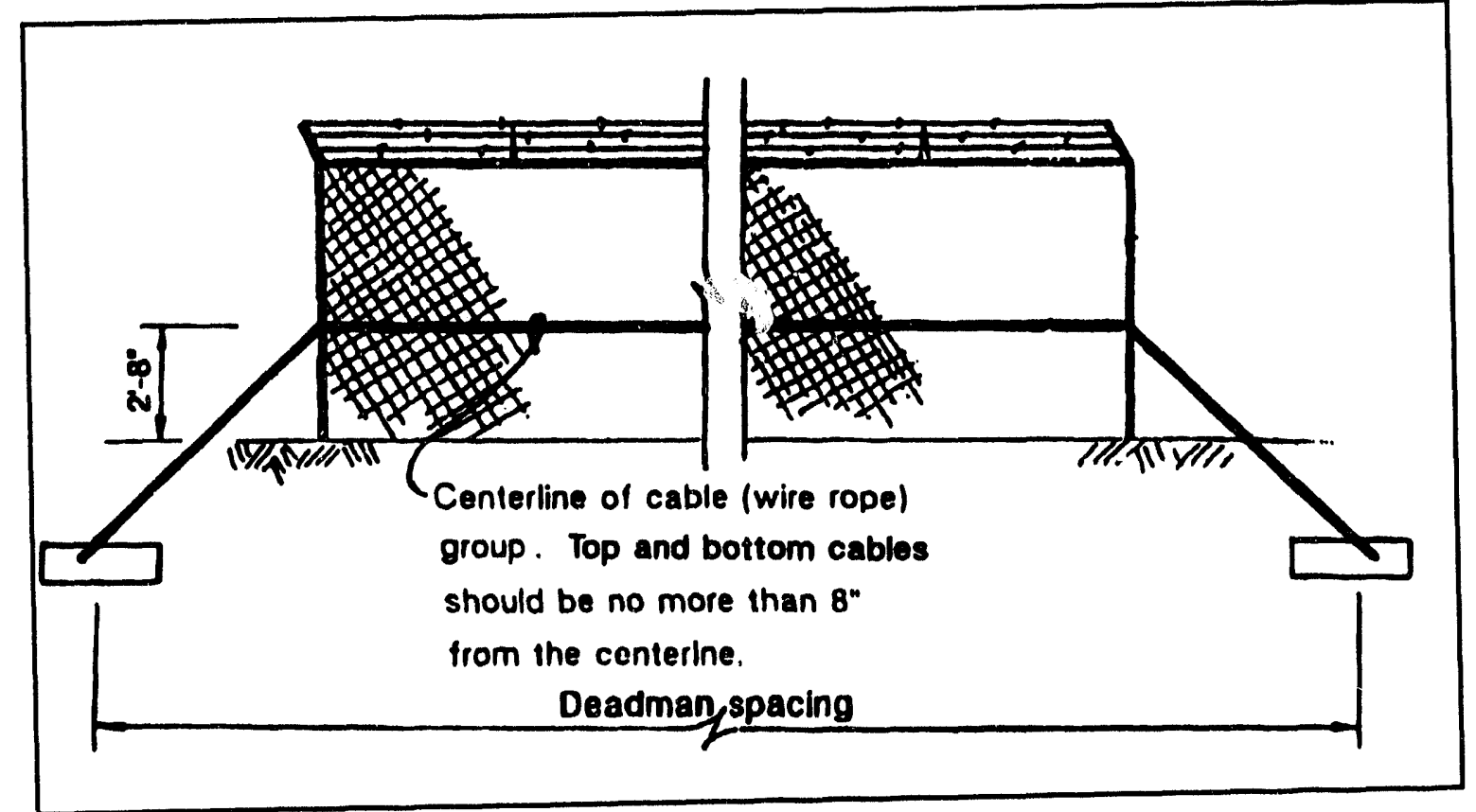

Figure 4.4 Chain-link fence with cables 


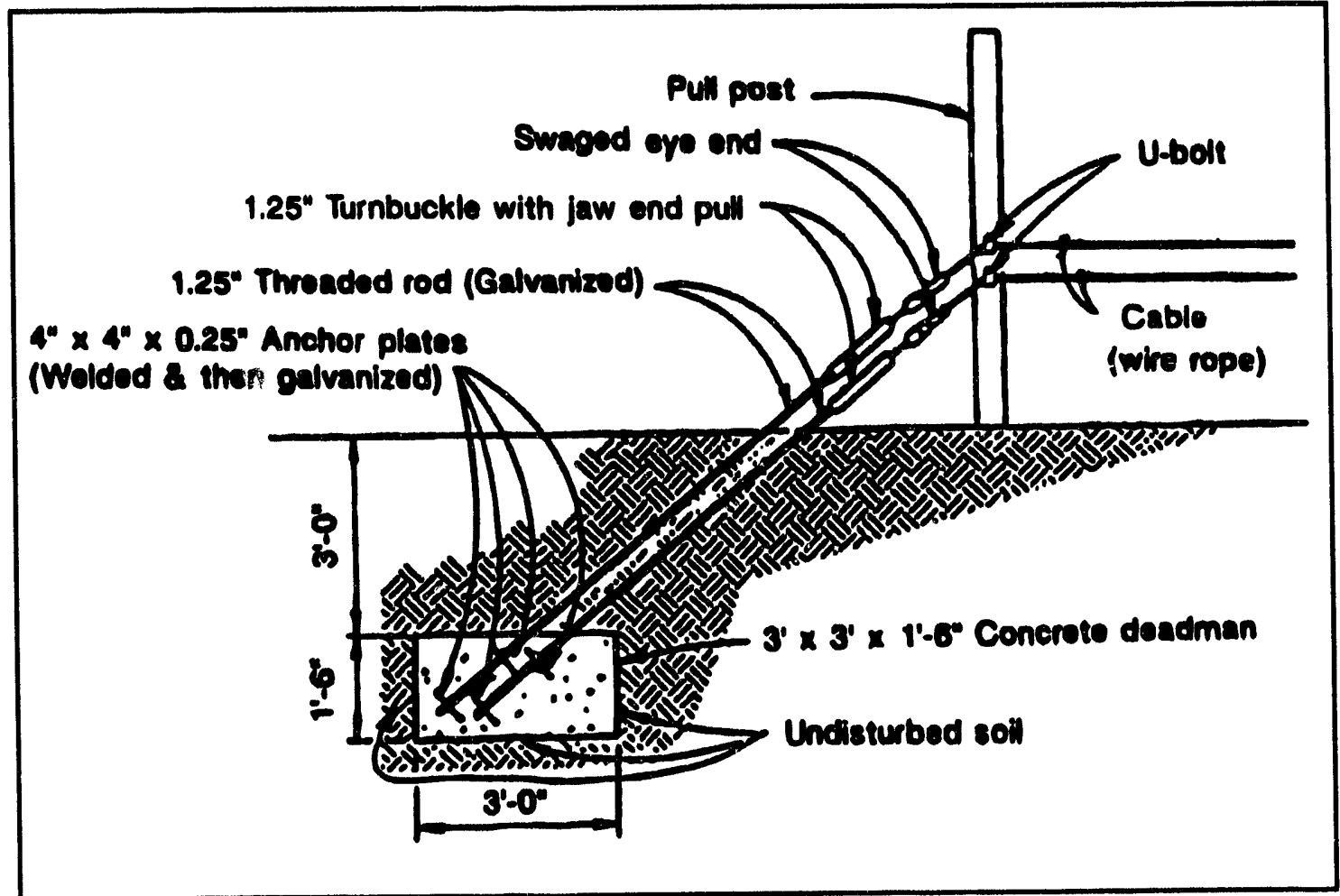

Figure 4.5 Deadman detail 


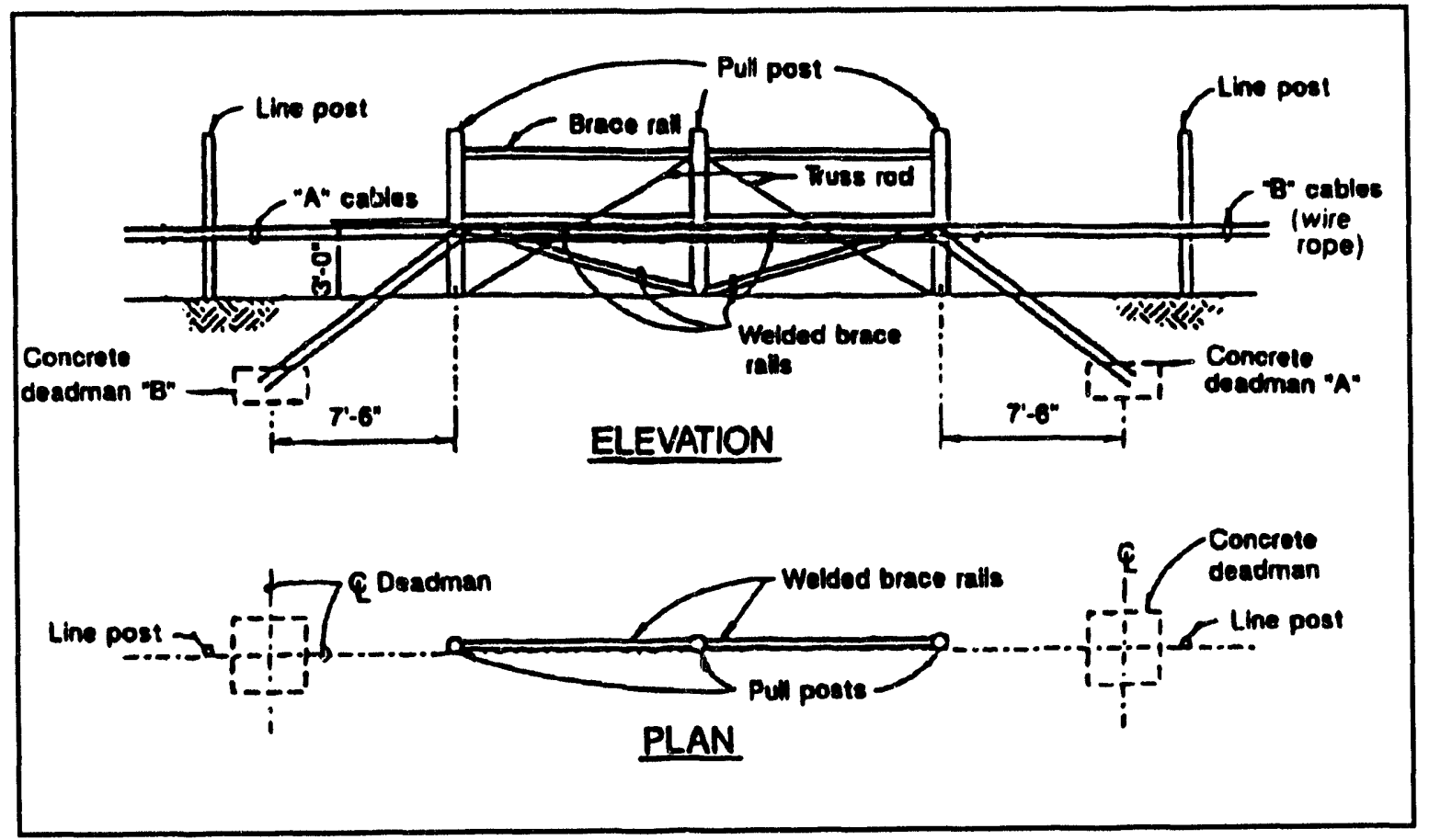

Figure 4.6 Intersect of two cable runs detail 


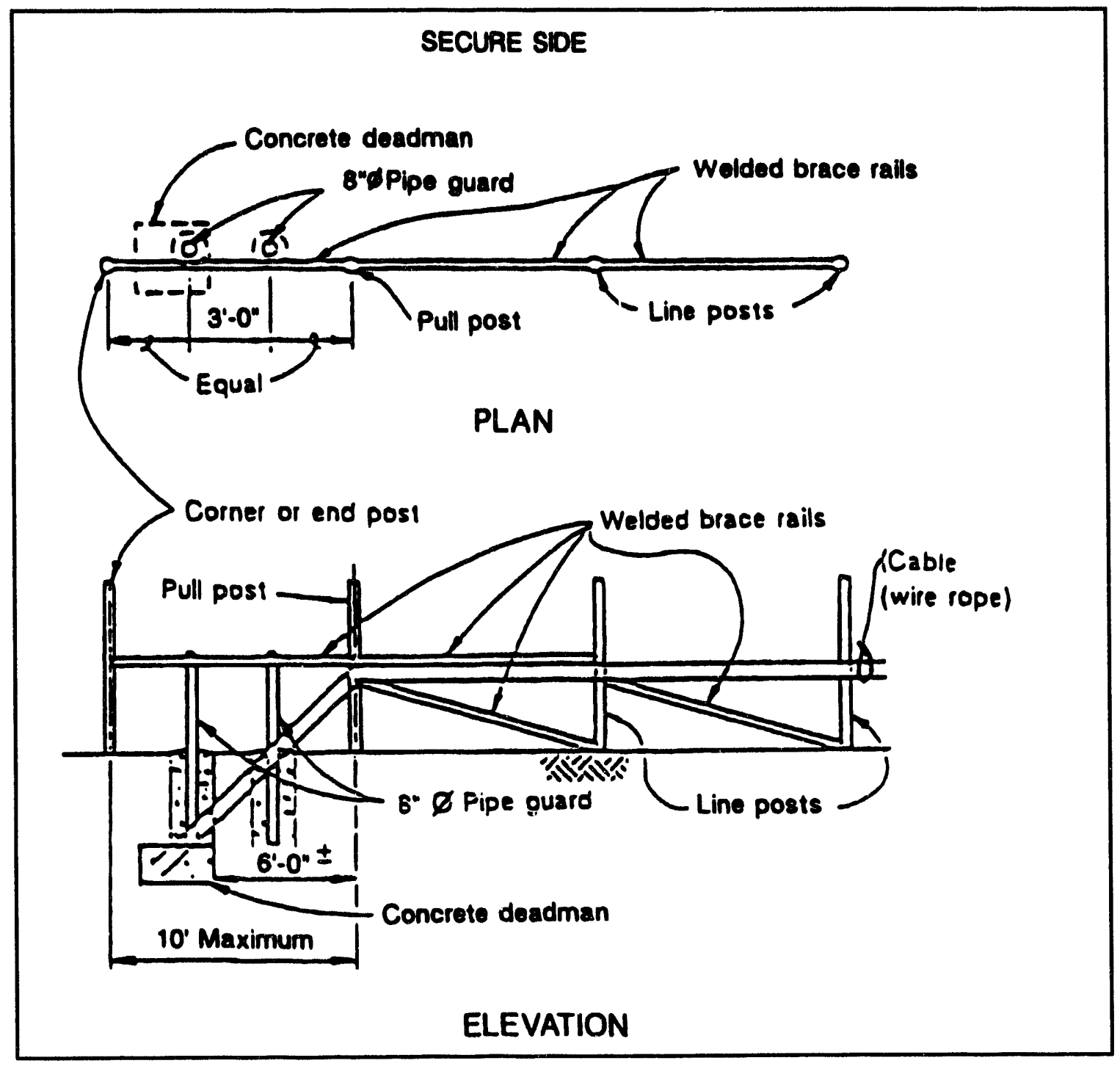

Figure 4.7 Corner or end post detail 


\section{SECTION 5 - ACTIVE VEHICLE BARRIER RATINGS}

\subsection{Purpose}

This section provides information on the crash ratings of active vehicle barriers. It contains the latest available information on vehicle barriers with established crash ratings based either on physical testing or analytical modeling and that will stop a vehicle at or in the immediate vicinity of the barrier. The information has been collected through research of government documents and analytical modeling. The procedure presented is an accepted way of demonstrating conformance; however, it is not exclusive. Other procedures based on sound scientific and engineering principles are also acceptable. If barriers other than those cited are used, or proposed for use, refer to section 7 .

\subsection{Active Vehicle Barriers}

Table 5.1 lists active vehicle barriers that have established ratings based on crash testing or analytic modeling and that will stop a vehicle at or in the immediate vicinity of the barrier. If active vehicle barriers are properly installed and have kinetic energy ratings equal to or greater than $\mathrm{KE}_{\max }$, no additional site features to reduce velocity are required. The use of active vehicle barriers with kinetic energy rating less than $\mathrm{KE}_{\max }$ requires the user to provide positive means for velocity reduction as discussed in section 6.

Table 5.1 Results of active vehicle barrier tests

\begin{tabular}{cc} 
Barrier & $\begin{array}{r}\text { Kinetic Energy } \\
(\mathrm{ft}-1 \mathrm{lb} \times 1000)\end{array}$ \\
\hline $\begin{array}{c}\text { Delta TT207S } \\
38 \text { in. high }\end{array}$ & $\geq \mathrm{KE}_{\max }$ \\
108 in. long & \\
(Drum Type) & \\
Delta TT207FM & $\geq \mathrm{KE}_{\max }$ \\
36 in. high & \\
144 in. long \\
(Plate type) \\
Delta TT212 \\
(Crash beam)
\end{tabular}


Table 5.1 Results of active vehicle barrier tests (continued)

\begin{tabular}{cc} 
Barrier & $\begin{array}{c}\text { Kinetic Energy } \\
(\mathrm{ft}-1 \mathrm{~b} \times 1000)\end{array}$ \\
\hline $\begin{array}{c}\text { Delta TT280 } \\
\text { Crash gate }\end{array}$ & $\geq \mathrm{KE}_{\max }$ \\
$\begin{array}{c}\text { Delta TT282 } \\
\text { Crash gate }\end{array}$ & $\geq \mathrm{KE}_{\max }$ \\
Delta SGC 1000 \\
Swing gate \\
$\begin{array}{c}\text { Delta TT281 } \\
38 \text { in. high }\end{array}$ & $201^{(1)}$ \\
Crash blocker & $\geq \mathrm{KE}_{\max }$ \\
Deita SC3000 & \\
Industrial cantilever gate & $362^{(1)}$ \\
Nasatka MSB III & $\geq \mathrm{KE}_{\max }$ \\
31 in. high \\
(Plate type)
\end{tabular}


Table 5.1 Results of active vehicle barrier tests (continued)

\begin{tabular}{cc} 
Barrier & $\begin{array}{c}\text { Kinetic Energy } \\
(\mathrm{ft}-\mathrm{lb} \times 1000)\end{array}$ \\
\hline $\begin{array}{c}\text { Barrier Concepts Inc. } \\
\text { VSB-F10 }\end{array}$ & $\geq \mathrm{KE}_{\max }$ \\
(Portable or fixed) & \\
B\&B Electromatic \\
Crash Beam \\
(R-25 Manual) \\
$\begin{array}{c}\text { Embassy Crash Gate } \\
\text { EGS-1 }\end{array}$ \\
\hline
\end{tabular}

(1) Kinetic energy is based on analytical modeling. 


\section{SECTION 6 - VELOCITY REDUCTION MEASURES}

\subsection{Purpose}

This section provides procedures to reduce vehicle impact velocity. Barriers with lesser kinetic energy ratings can be used if the impact velocity can be reduced from the maximum velocity. The maximum velocity sihould be used if it cannot be demonstrated that site topography will provide velocity reduction.

\subsection{Determining Reduced Vehicle Velocity}

The information below can be used to determine the velocity that vehicles can attain as they approach vehicle barriers. This information addresses attainable velocity on paved curves and on straight paved roads and is conservative for off-road approaches. Additional information on vehicle velocity reduction can be found in NUREG/CR 4250, Barriers: Emphasis on Natural Features.

\subsubsection{Velocity on Curves}

Figure 6.1 can be used to determine the attainable vehicle velocity on curves. This figure assumes a flat paved roadway with a coefficient of friction of 0.6 . This is a representative coefficient for most dry roads and should provide conservative resuits across a wide range of surface conditions. Determine the velocity based on the radius of curve to the middle of the road. At velocities greater than those shown in figure 6.1 for the various radii, the vehicle will begin to skid.

\subsubsection{Velocity on Straight Roads}

Figure 6.2 car: be used to determine the attainable velocity of vehicles on straight roads. This figure shows vehicle velocity from a dead start on a dry road and includes data for flat roads and three different uphill grades. Figure 6.2 should provide conservative results for other road surface conditions. Do not use figure 6.2 for downhill grades. Where possible, avoid downhill grades toward the vehicle barrier system. Using the data appropriate for the grade of the road, determine the velocity based on the distance between the point at which the vehicle starts from a dead stop and the vehicle barrier. If the vehicle has an initial velocity before it begins its run at the barrier, refer to figure 6.2 at the initial velocity and read the distance corresponding to that velocity. Move to the right from that corresponding distance by the distance to the barrier and read the velocity associated with that new distance.

\subsubsection{Traffic Obstacles}

Traffic obstacles such as those shown in figure 6.3 can be used to slow vehicles approaching a vehicle barrier on existing roads without curves or on roads with curves of insufficient radius to slow traffic. Traffic obstacles include oil drums, planters, Jersey barriers, and various concrete or steel objects. These obstacles will not stop a vehicle on impact, but they will slow it down or cause the driver to drive around them, which will also slow the vehicle. Use the obstacles to create " $S$ " curves in the road as illustrated in figure 6.4. Use figure 6.5 to determine the required spacing in a straight section of two-lane road using barriers or groups of barriers with an effective width of 10 feet. Use wider barriers for lane widths greater than 12 feet. Figure 6.5 can conservatively be used for establishing obstacles in off-road approaches as well. 


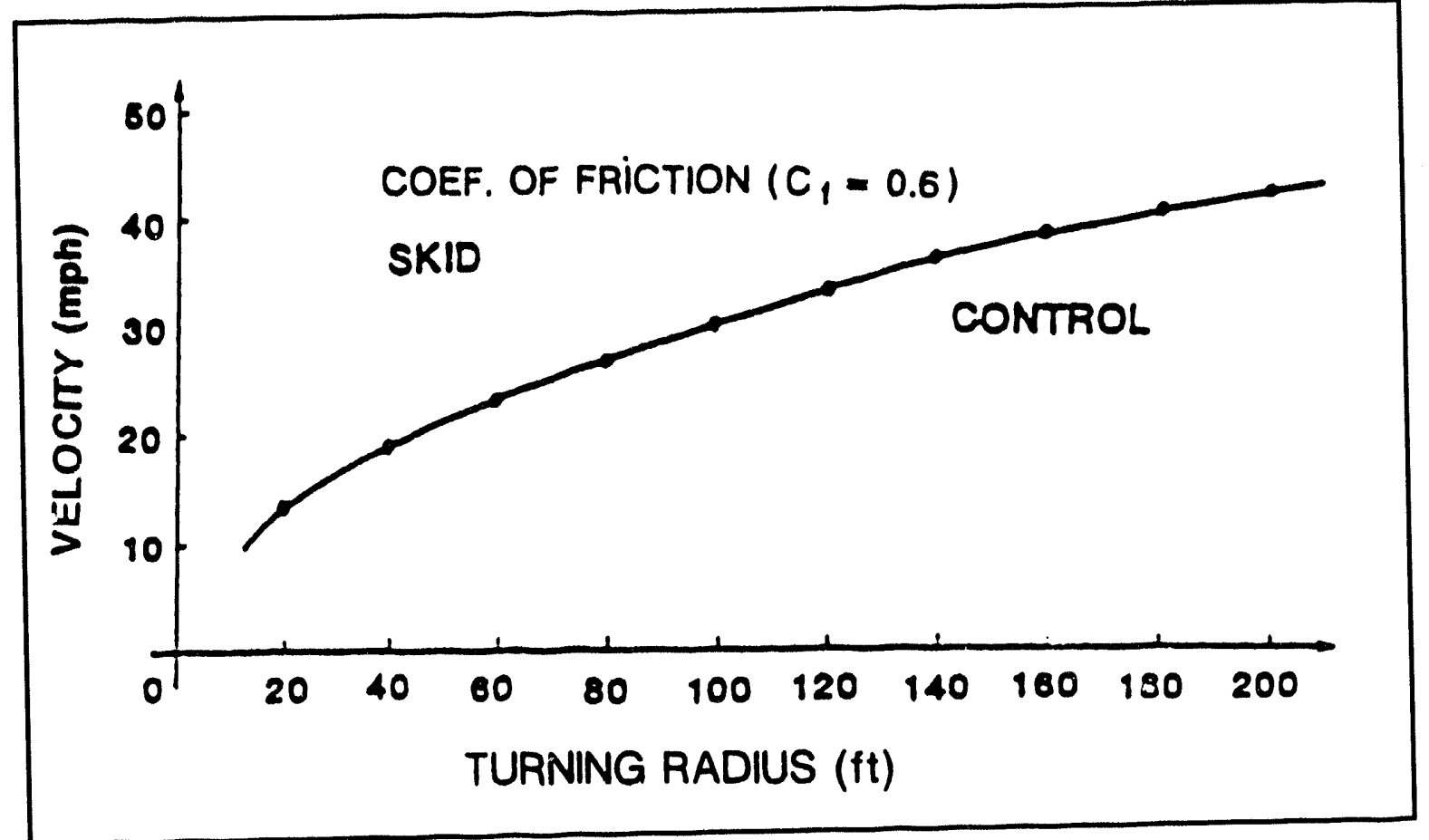

Figure 6.1 Vehicle velocity on curves 


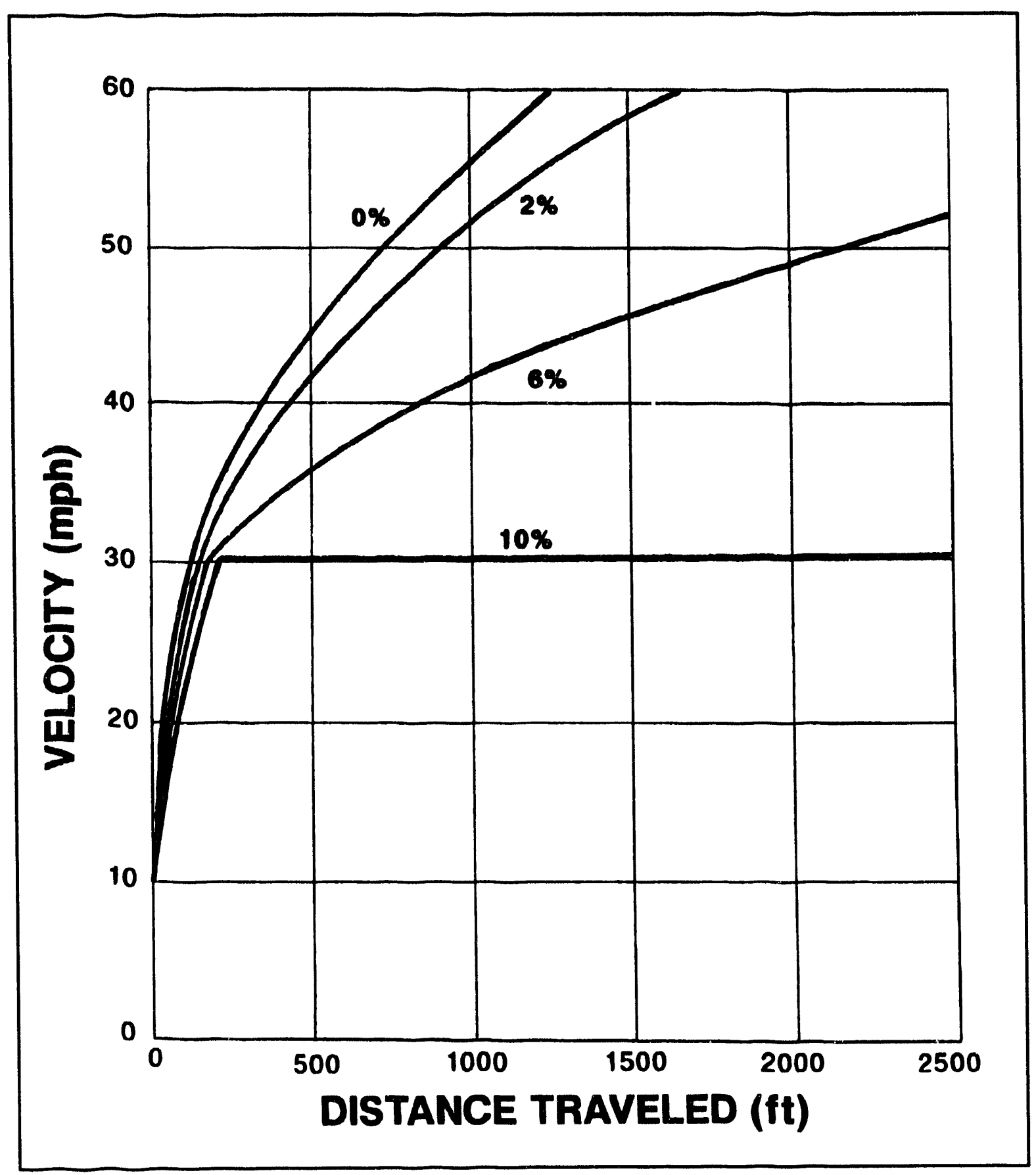

Figure 6.2 Vehicle velocity from dead start 


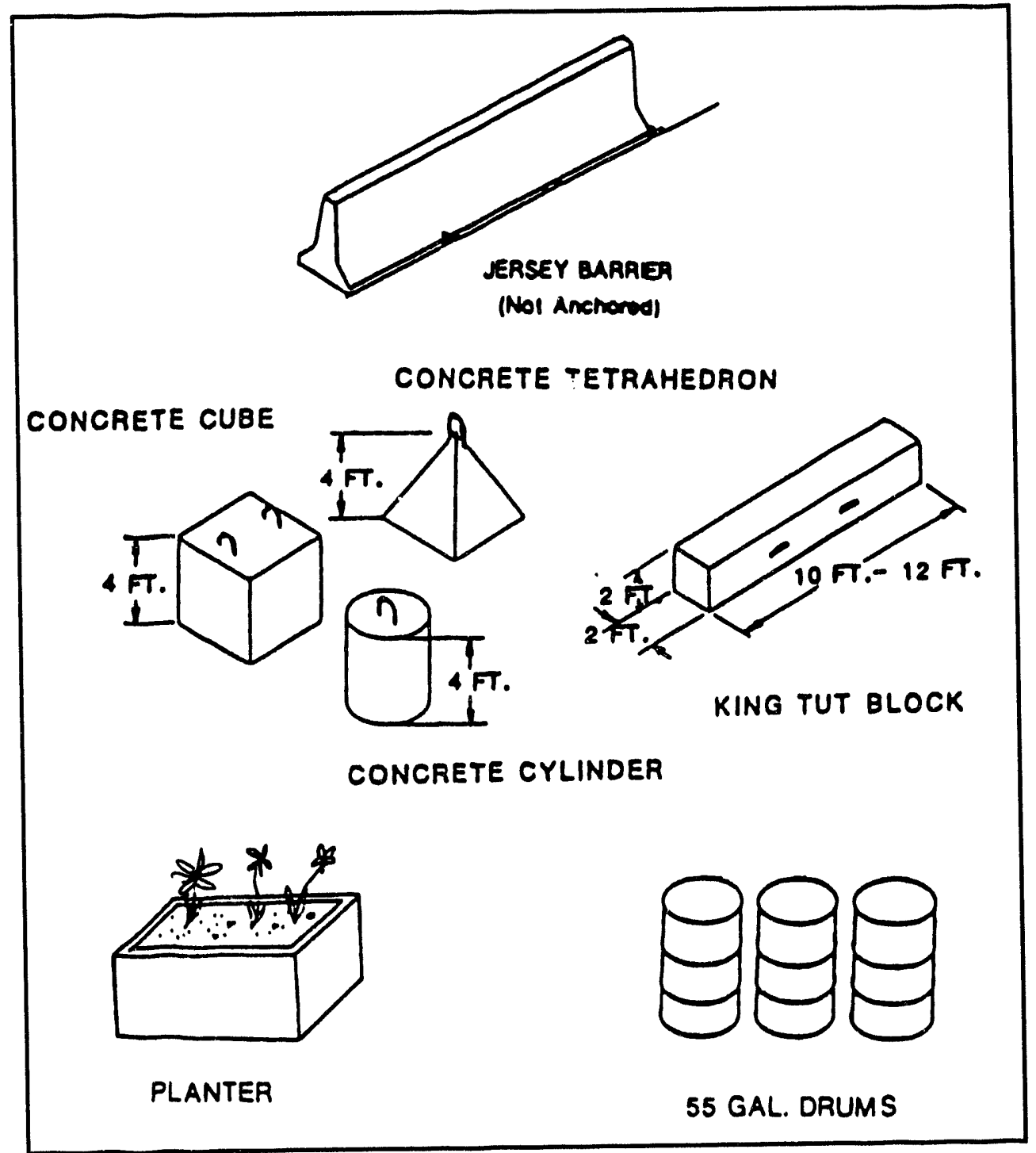

Figure 6.3 Barriers used as traffic obstacles 


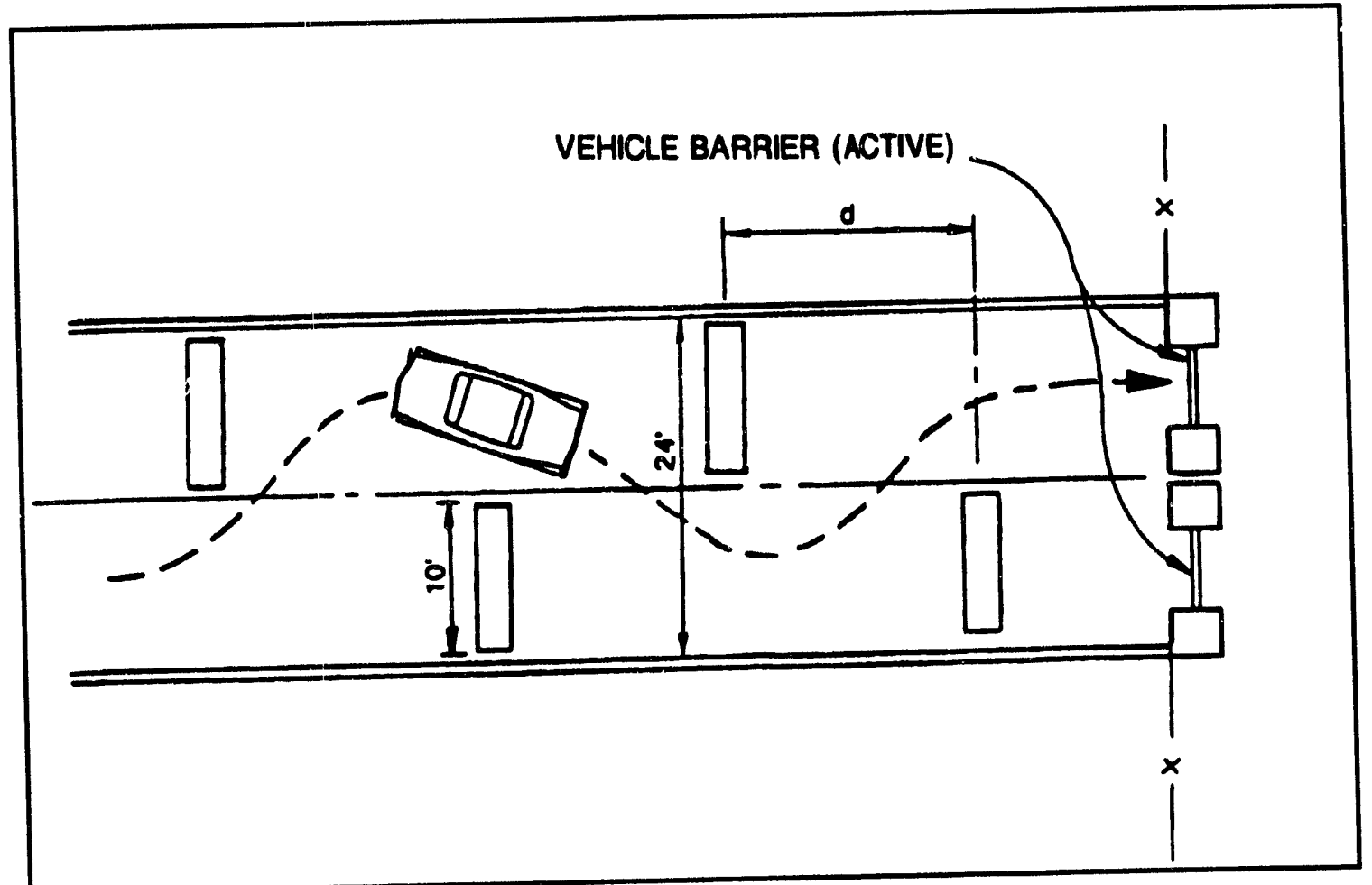

Figure 6.4 Application of traffic obstacles 


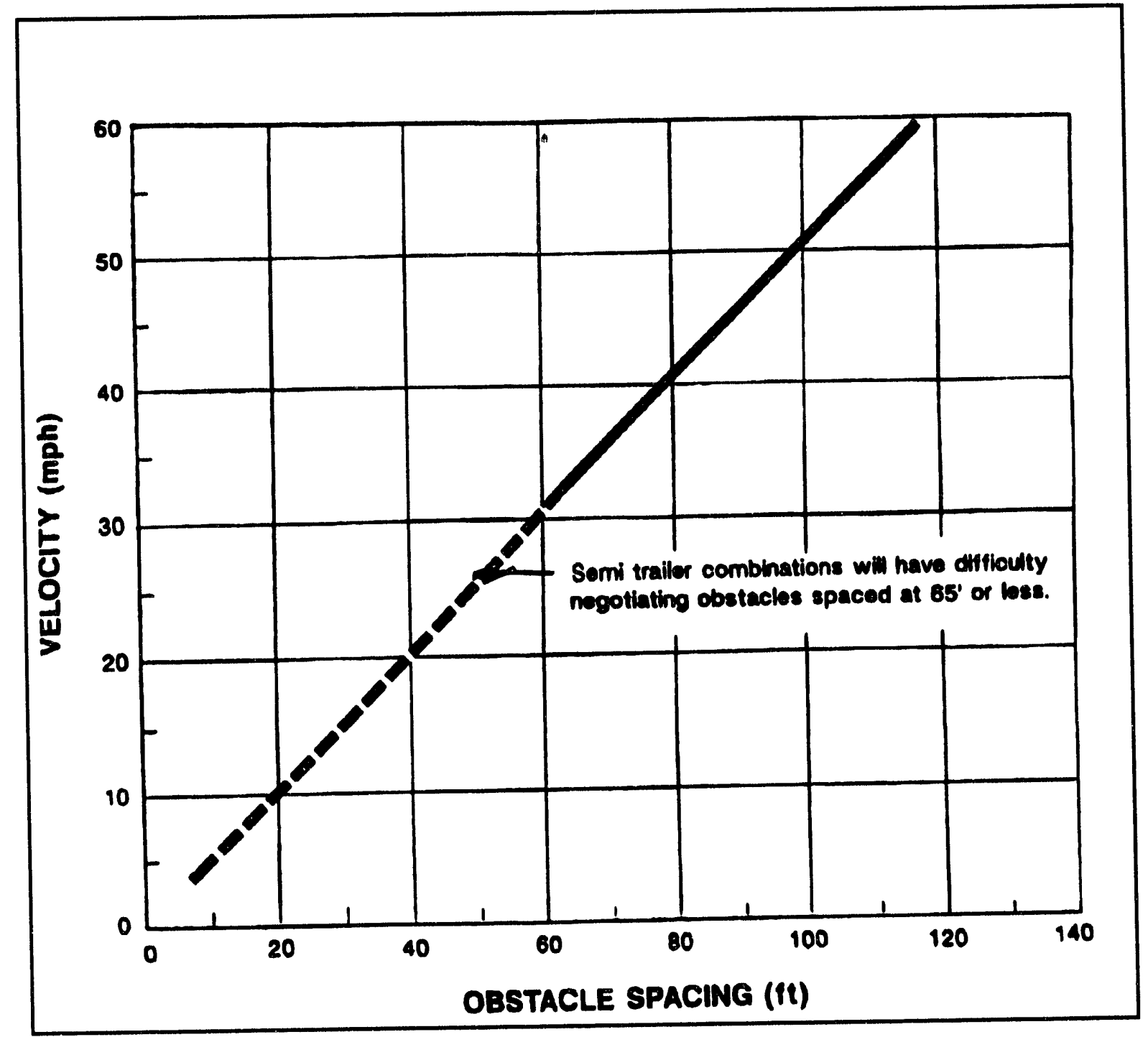

Figure 6.5 Obstacle spacing vs. vehicle velocity 


\subsubsection{Examples}

\subsubsection{Curves}

There is a maximum velocity at which a vehicle can negotiate a curve. Using the graph in figure 6.6 , the traction coefficient, the initial velocity, and the measurements for the radius of curvature, the maximum velocity for each curve can be determined. For example, figure 6.6 shows that if the radius of the curve is 160 feet, the maximum velocity at which the curve can be negotiated is $38.5 \mathrm{mph}$. Since we have assumed no acceleration on curves, the resultant velocity is the velocity at which the vehicle can negotiate the curve.

\subsubsection{Straight Paths From a Dead Start}

To find the velocity of a vehicle at the end of a straight path starting at a dead start, follow the example presented in figure 6.7. In this example, the road will be straight, level (0 percent gradient), and the distance that the vehicle travels will be 500 feet. The following steps demonstrate the procedure to use.

(a) Find 500 feet on the horizontal axis and label this point $S$.

(b) Draw a vertical line up from point $S$ until it intersects the 0 percent gradient curve.

(c) Draw a horizontal line from the intersection point to the vertical axis.

(d) Read the maximum velocity, $V_{S}$, from the vertical axis, $45 \mathrm{mph}$.

\subsubsection{Straight Paths With an Initial Velocity}

To find the velocity at the end of a straight path when the vehicle has an initial velocity, follow the example presented in figure 6.8. In this example, the roadway will be level ( 0 percent gradient), the initial velocity will be $40 \mathrm{mph}$, and the distance traveled, $s$, will be 700 feet. The following steps explain the procedure to be used.

(a) Label the initial velocicy $V_{T}=40 \mathrm{mph}$ on the vertical axis of the graph.

(b) Draw a horizontal line from $V_{T}=40$ to the point where that line intersects the 0 percent gradient curve.

(c) Draw a vertical line down from this intersection point to the horizontal axis.

(d) Read the acceleration distance at this point from the horizontal axis, 380 feet.

(e) Label the point $T=380$ feet.

(f) Add the distance, $S$, (in feet) to the value of $T$ :

$$
S+T=700+380=1,080 \text { feet }
$$

(g) Find the distance $S+T(1,080$ feet) on the horizontal axis and label this point $Z$.

(h) Draw a vertical line up from point $Z$ to the 0 percent gradient curve.

(i) Draw a horizontal line from the point of intersection to the velocity axis.

(j) Read the velocity, $v_{z}$, from the vertical axis, $56 \mathrm{mph}$.

\subsubsection{Traffic Obstacles}

The use of traffic obstacles is very effective in slowing vehicles on existing roads of insufficient radius. The placed obstacles include any mass that will slow down a vehicle or cause a driver to drive around them. Figure 6.9 presents an example based on a desired vehicle velocity to determine traffic obstacle spacing. From the graph, a vehicle velocity of $25 \mathrm{mph}$ is chosen 


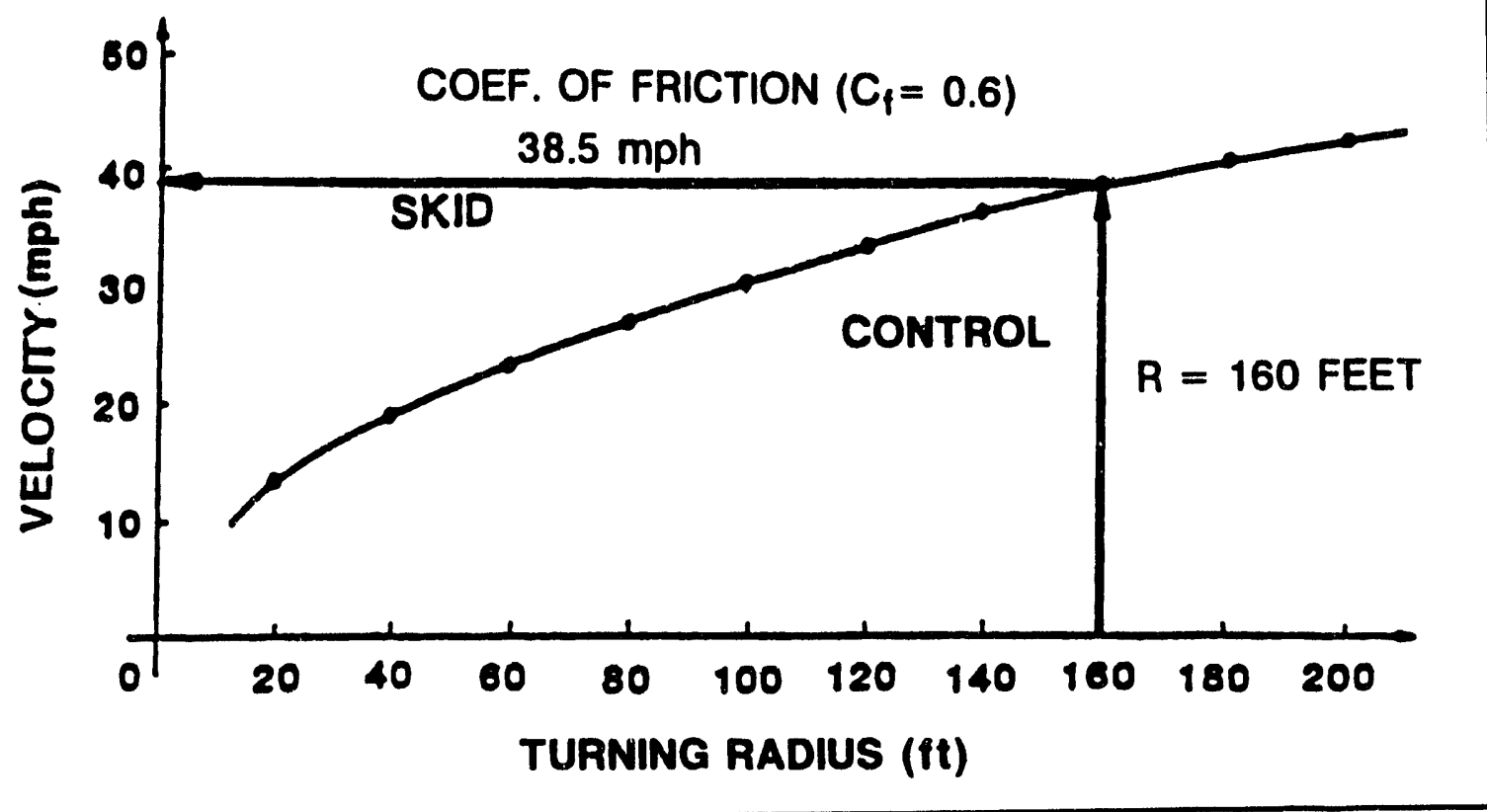

Figure 6.6 Example - Vehicle velocity on curves 


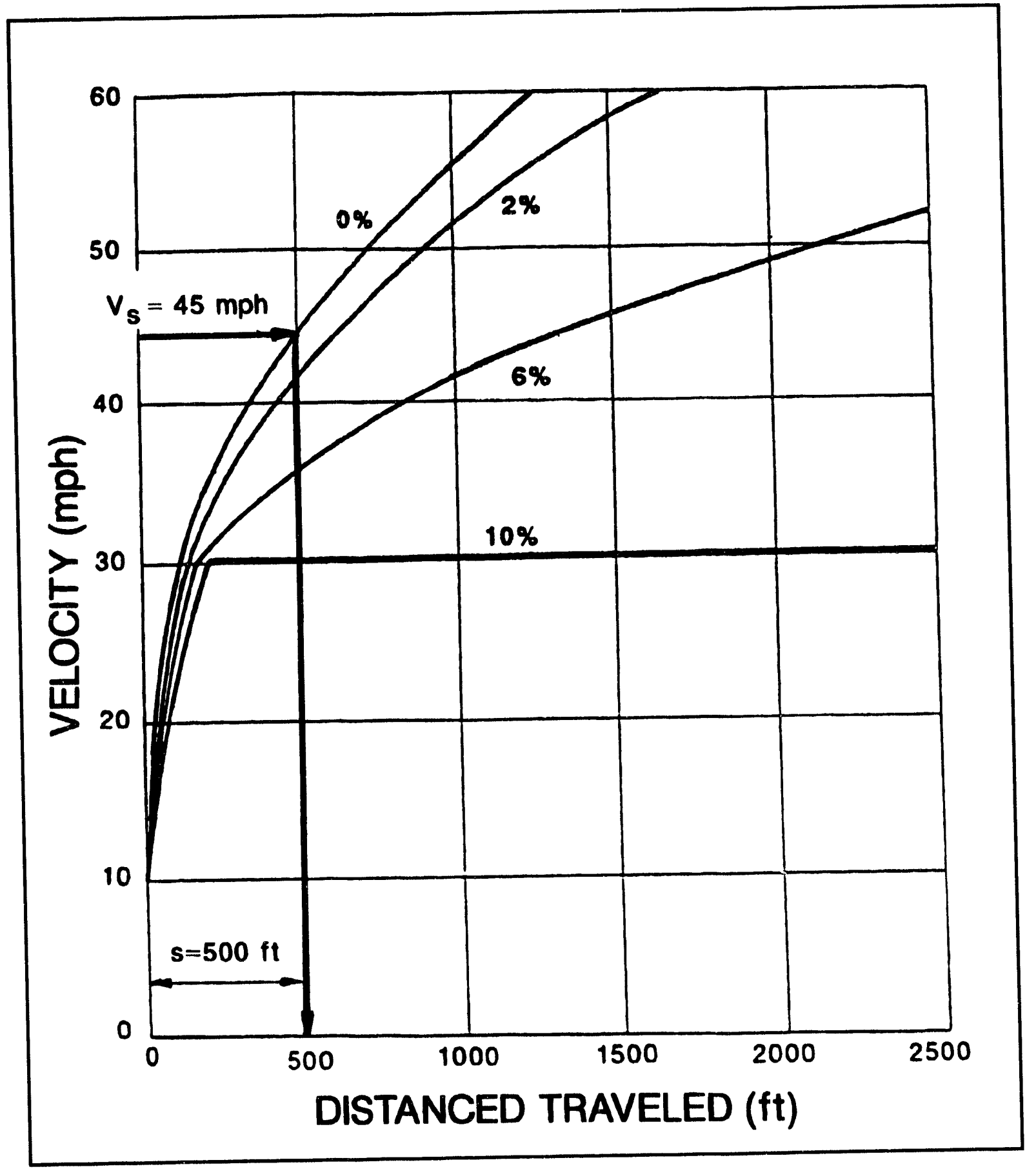

Figure 6.7 Example - Vehicle velocity from dead start 


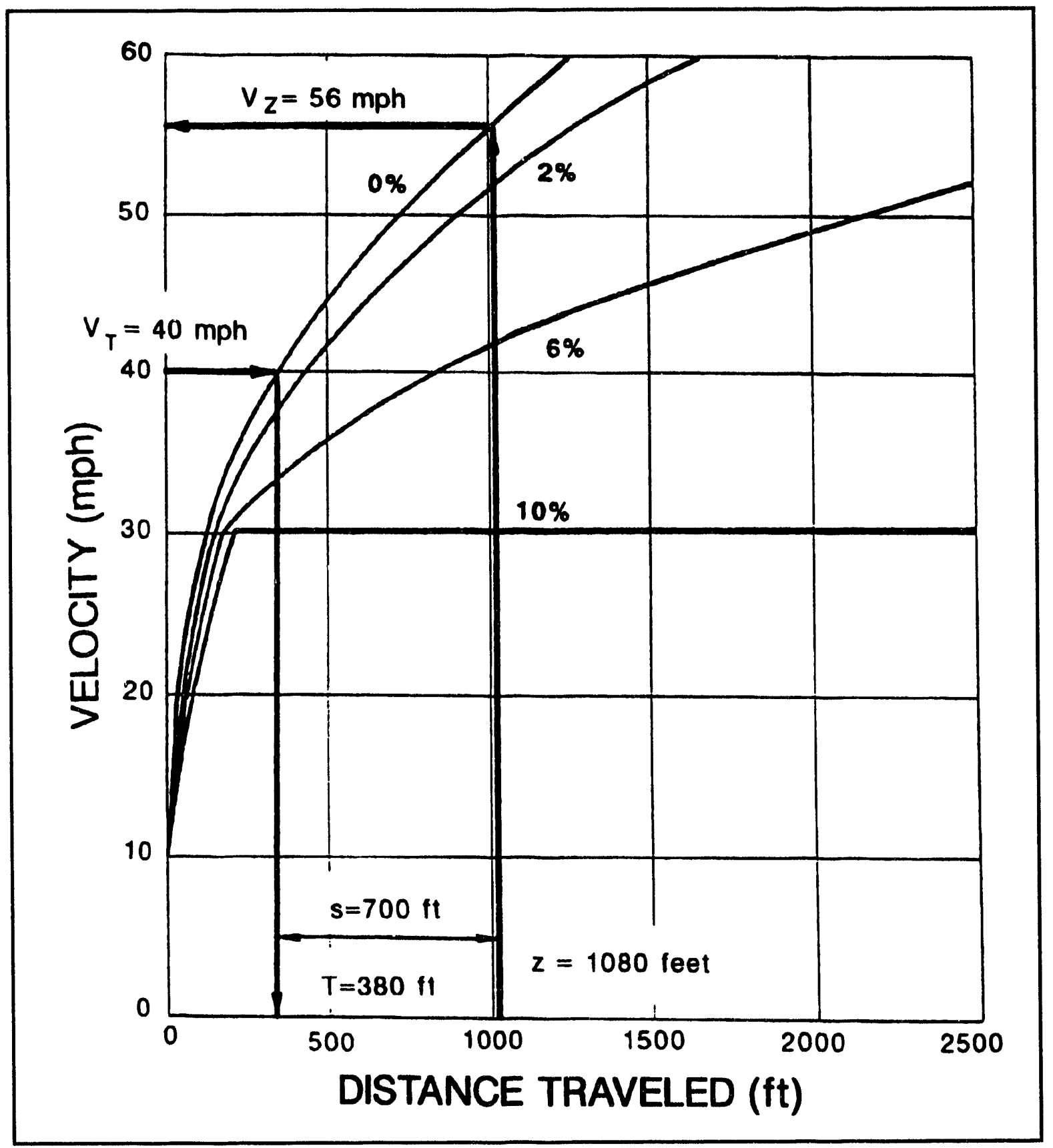

Figure 6.8 Example - Vehicle velocity with initial velocity 


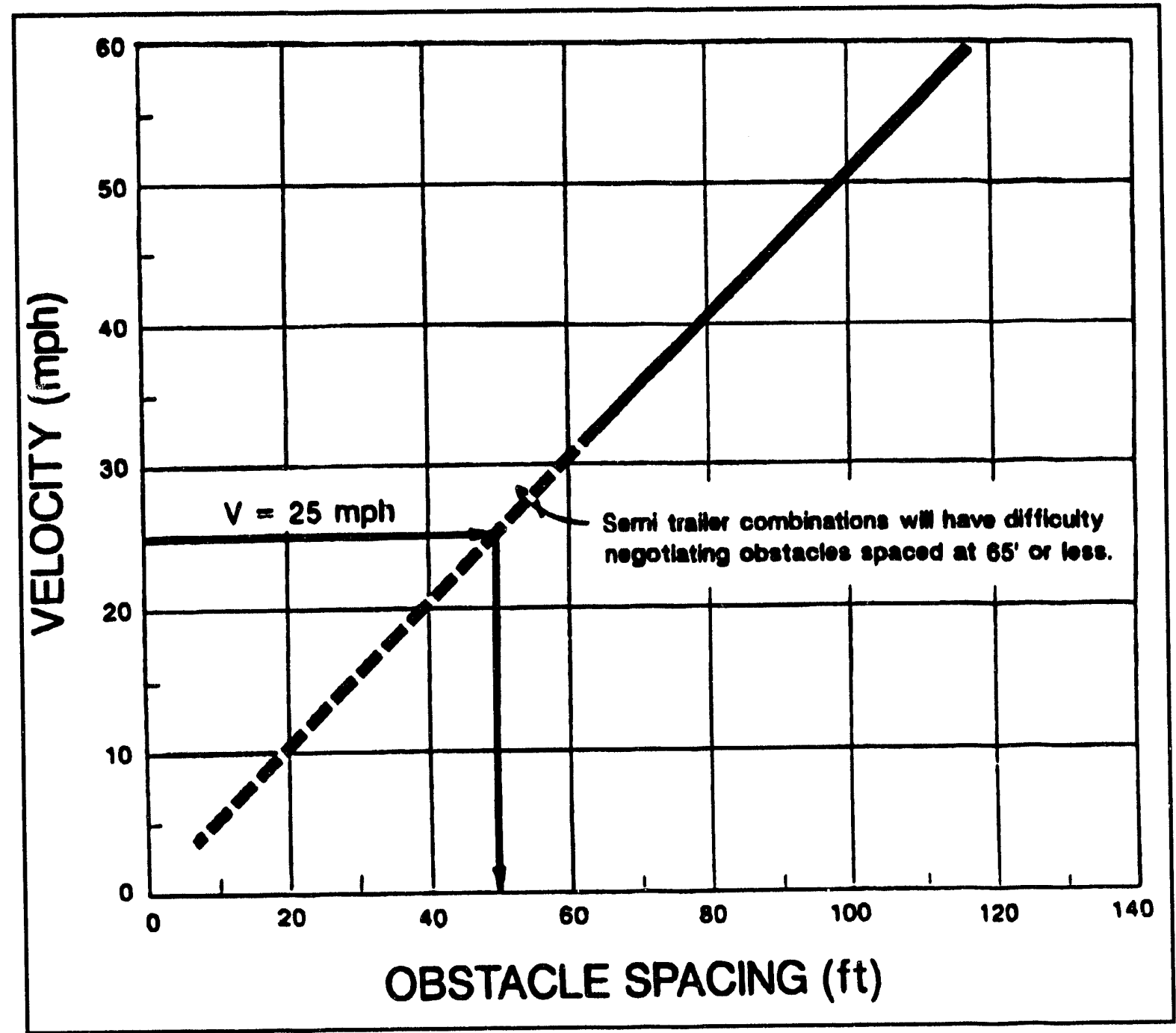

Figure 6.9 Example - Obstacle spacing vs. vehicle velocity 
and a parallel line to the horizontal axis is drawn to the point where that line intersects the diagonal line. At this point, draw a vertical line down from this intersection point to the horizontal axis. For this example, the obstacle spacing required equals 49 feet as read on the horizontal axis.

\subsection{Determining Kinetlc Energy}

The design kinetic energy is calculated by using equation 2-1 with the design basis velocity and the combined gross vehicle weight listed in Regulatory Guide 5.68.

\subsection{Barrier Selection}

After calculating the kinetic energy, the tables in sections 4 and 5 can be used to select a barrier. Enter the appropriate table and select a barrier that has an equal or higher rating than the kinetic energy calculated as indicated in paragraph 6.3. 


\section{SECTION 7 - OTHER VEHICLE BARRIERS}

If other vehicle barriers are used, their crash ratings must be established. This can be accomplished by a qualified testing organization performing full-scale crash testing by approved procedure or by a dynamic nonlinear analysis performed by qualified personnel. 


\section{SECTION 8 - DOCUMENTATION}

Documentation guidelines are contained in

Regulatory Guide 5.68. 


\section{SECTION 9 - CONCLUSIONS}

This manual provides a simplified procedure that may be used to select both passive and active vehicle barriers to prevent intrusion by the design basis vehicle threat adopted by the U.S. Nuclear Regulatory Commission. 


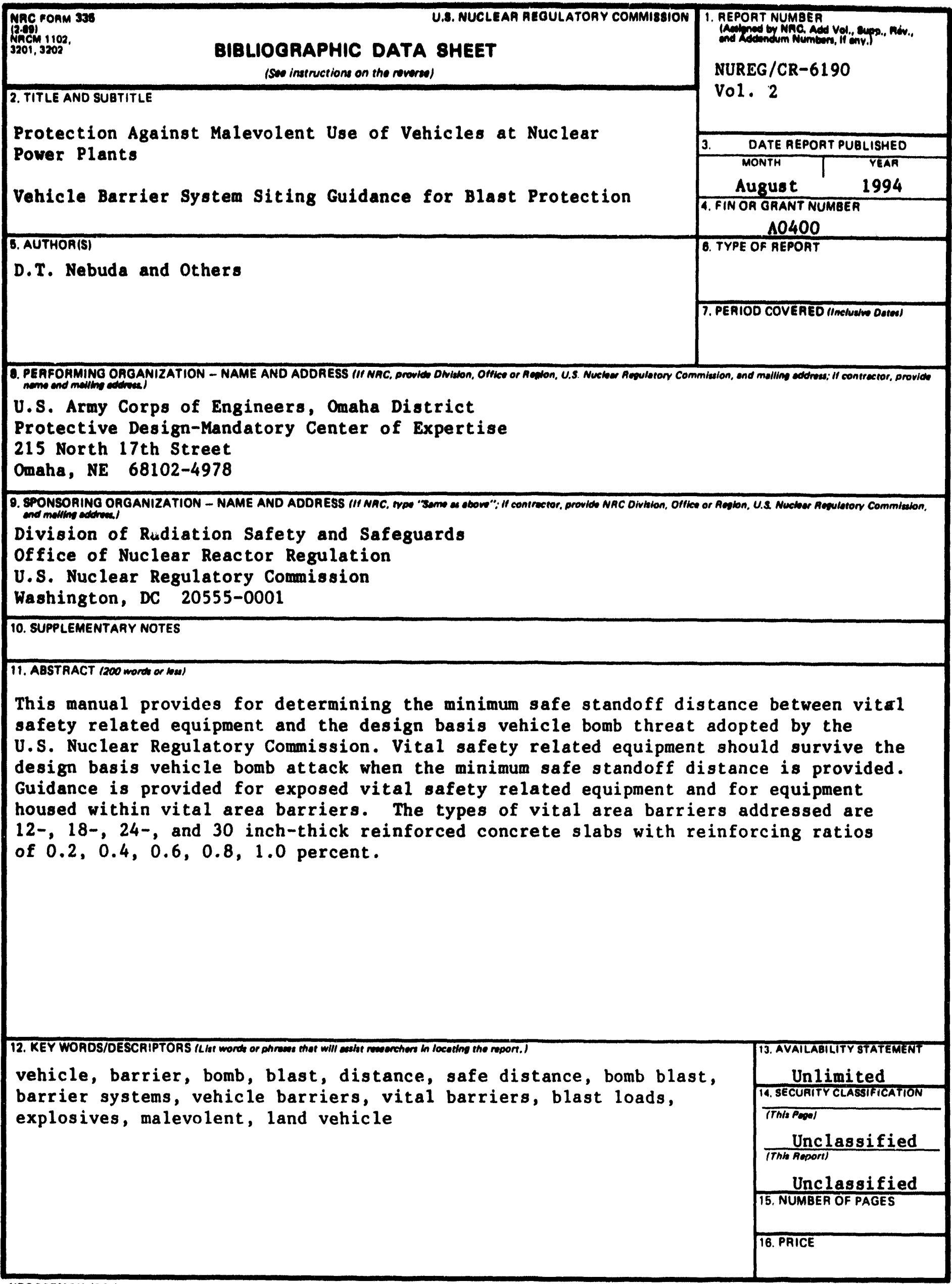



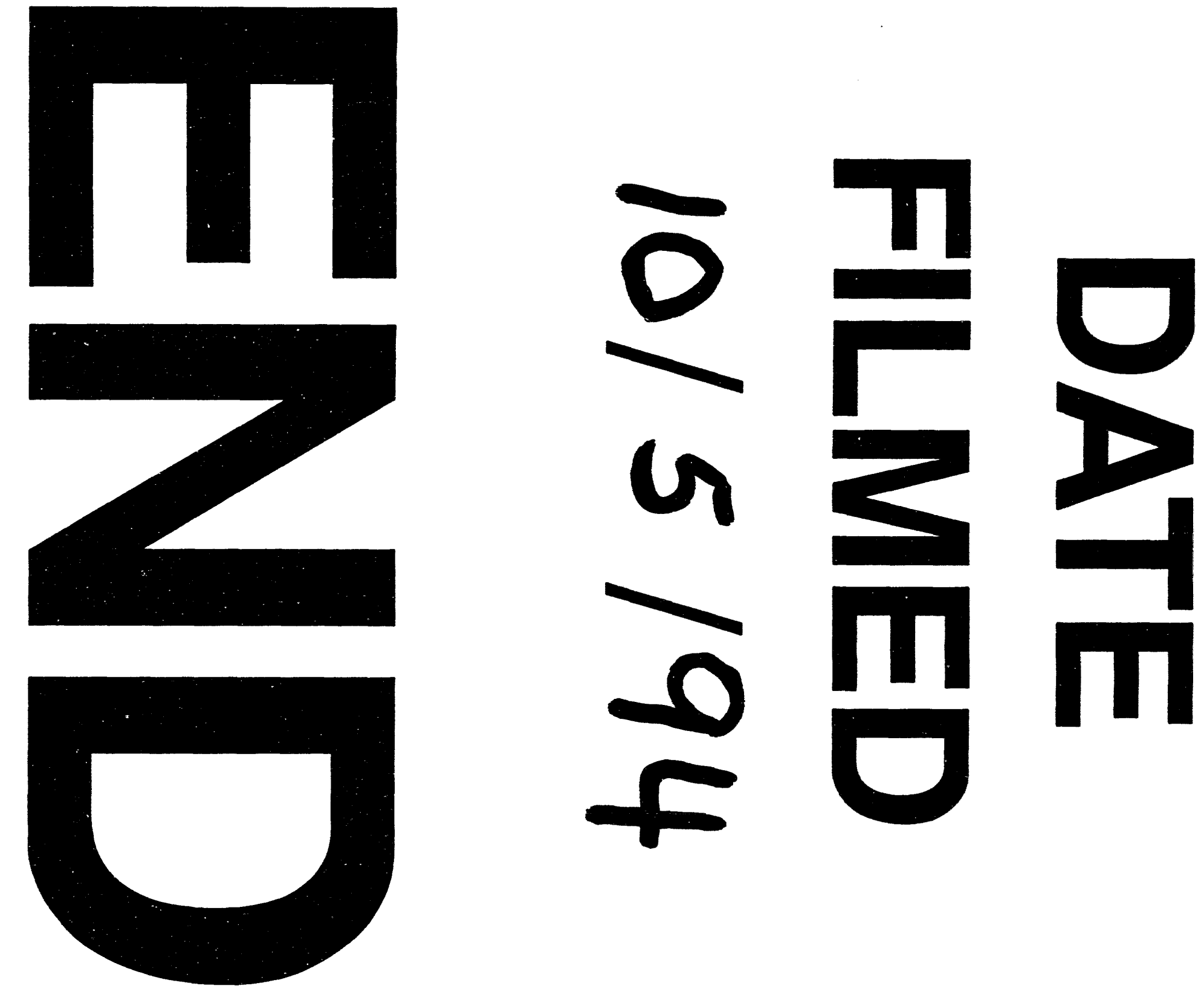


$$
\begin{aligned}
& - \\
& \text { - }
\end{aligned}
$$

